Published in final edited form as:

Gastroenterology. 2008 May ; 134(6): 1641-1654. doi:10.1053/j.gastro.2008.03.002.

\title{
Cellular and Molecular Mechanisms of Liver Injury
}

\author{
Harmeet Malhi and Gregory J. Gores \\ Miles and Shirley Fiterman Center for Digestive Diseases, Mayo Clinic, Rochester, Minnesota
}

\begin{abstract}
Derangements in apoptosis of liver cells are mechanistically important in the pathogenesis of endstage liver disease. Vulnerable hepatocytes can undergo apoptosis via an extrinsic, death receptormediated pathway, or alternatively intracellular stress can activate the intrinsic pathway of apoptosis. Both pathways converge on mitochondria, and mitochondrial dysfunction is a prerequisite for hepatocyte apoptosis. Persistent apoptosis is a feature of chronic liver diseases, and massive apoptosis is a feature of acute liver diseases. Fibrogenesis is stimulated by ongoing hepatocyte apoptosis, eventually resulting in cirrhosis of the liver in chronic liver diseases. Endothelial cell apoptosis occurs in ischemia-reperfusion injury. Natural killer and natural killer T cells remove virus-infected hepatocytes by death receptor-mediated fibrosis. Lastly, activated stellate cell apoptosis leads to slowing and resolution of apoptosis. This review summarizes recent cellular and molecular advances in the understanding of the injury mechanisms leading to end-stage liver disease.
\end{abstract}

\begin{abstract}
Liver injury encountered in clinical practice is arbitrarily divided into acute and chronic, based on the duration or persistence of liver injury. Acute insults are mostly surmountable with rapid resolution upon elimination of the injurious agent and complete restitution of normal liver architecture and function without enduring evidence of the preceding insult. Progressive fibrosis is the hallmark of chronic liver injury; it can eventually result in cirrhosis, liver failure, or hepatocellular carcinoma. This distinction between acute and chronic liver injury is a mechanistic oversimplification. Chronic liver injury reflects, in part, continuous acute liver injury extended over time. The consequences of continuous acute liver injury are what drive hepatic fibrogenesis. This process became especially apparent when effective therapy for chronic hepatitis B became available. Many patients with end-stage liver disease thought to warrant liver transplantation for survival had significant recovery with antiviral therapy and no longer required urgent transplantation. Furthermore, with the recognition that hepatic fibrogenesis has a reversible component; inhibition of liver injury has become a potential therapeutic strategy for advanced liver disease. Thus, an understanding of the mechanisms mediating liver injury is of biomedical and clinical relevance. Recent advances in understanding the cellular processes and molecular signaling that mediate liver injury are summarized in this review. The first half focuses on mechanistic insights, and in this section references to nonliver systems serve as paradigms; the latter half focuses on select liver-specific disease processes.
\end{abstract}

\footnotetext{
Address requests for reprints to: Gregory J. Gores, MD, Miles and Shirley Fiterman Center for Digestive Diseases, Mayo Clinic, 200 First Street Southwest, Rochester, Minnesota 55905. fax: (507) 284-0762. e-mail: gores.gregory@ mayo.edu.

The authors report that they have no conflict of interest.

The authors thank Erin Nystuen-Bungum for excellent secretarial support.
} 


\section{Mechanisms of Liver Cell Death}

\section{Apoptosis and Necrosis}

Nomenclature in the literature refers to apoptotic cell death and necrotic cell death in diseased livers. Apoptosis is defined morphologically on the basis of cellular rounding up, cytoplasmic shrinkage (pyknosis), chromatin condensation, and nuclear fragmentation (karyorrhexis). Effector caspase (proteases that cleave at aspartate residues) activation is required for the acquisition of this morphology. Necrotic cell death has the morphology of oncosis (cell swelling due to the inability to maintain cellular ion gradients), karyolysis, and rupture of the plasma membrane. While definitions are useful as broad categories, understanding the minute mechanisms that lead to cell death and ensuing injury are more important than allotting modes of cell death to a particular liver disease. Suffice it to say that in the liver, morphologically observed cell death can be apoptotic or necrotic or a combination of the two. Furthermore, the same stimulus can result in either morphology. ${ }^{1,2}$ It is conceivable that on a cellular basis, necrosis in the liver is the result of overwhelming or dysregulated apoptosis. For example, exaggerated mitochondrial dysfunction from "apoptotic" signaling cascades can result in cellular adenosine triphosphate depletion and necrotic morphology. Hepatocytes are the most numerous cell type in the liver, and their apoptosis is prominent in liver injury. ${ }^{3-5}$ Councilman bodies, described by the pathologist William T. Councilman (1854-1933), in the liver of patients with yellow fever result from apoptotic death of individual hepatocytes. ${ }^{6}$ On careful examination, hepatocyte apoptosis can be identified in virtually all forms of liver injury. $4,7-$ 10 Apoptosis of other cellular compartments is also important. For example, sinusoidal endothelial cell apoptosis is observed in ischemia-reperfusion injury, and failure of activated stellate cell apoptosis promotes fibrosis. The M30 neoantigen is one example of an emerging clinical applicability of the apoptosis cascade. ${ }^{11}$ This epitope is formed by proteolytic cleavage of cytokeratin 18 by caspase 3 at Asp396 position. It is readily detectable in plasma by enzymelinked immunosorbent assay. Circulating levels are increased in patients with chronic liver disease, and highest levels are found in patients with cholestasis or cholangitis. ${ }^{12}$ Levels in hepatic graft-versus-host disease are elevated and correlate with response to therapy. ${ }^{13} \mathrm{In}$ patients with steatohepatitis, serum levels of M30 correlate with liver levels and inflammation. 14 Thus, a biomarker reflecting hepatocyte apoptosis may eventually be important in establishing and monitoring therapy in human liver diseases. The appearance of serum cytokeratin 18 degradation products in virtually all liver diseases also highlights the role of caspases in liver tissue injury. Apoptosis can be initiated from any membrane-defined organelle in the cell. In this review, we emphasize this mechanistic concept.

\section{Mitochondria}

Mitochondrial dysfunction is the commitment step in hepatocyte cell death, and hepatocyte cell death is dependent on mitochondria. ${ }^{15}$ Apart from the well-recognized metabolic functions of mitochondria such as the respiratory chain, the inner and outer mitochondrial membranes also isolate a number of proapoptotic proteins within the intermembrane space. Mitochondrial outer membrane permeabilization leads to the release of these apoptosis mediators, cytochrome $c$, second mitochondrial activator of caspase/direct IAP binding protein with low $\mathrm{pI}$ (SMAC/ DIABLO), HtrA2/Omi, apoptosis-inducing factor, and endonuclease G. ${ }^{16}$ Activation of downstream effector caspases ensues, resulting in the typical morphologic changes of apoptosis. Mitochondrial outer membrane permeabilization occurs selectively, mediated via activated Bax or Bak (vide infra) or secondary to mitochondrial permeability transition. ${ }^{17}$ For example, in ischemia-reperfusion injury, the mitochondrial permeability transition pore (which is composed of the voltage-dependent anion channel, adenosine nucleotide transporter, and cyclophilin D) upon activation leads to influx of solutes and ions, swelling of the mitochondrial matrix, and rupture of the outer mitochondrial membrane, releasing proapoptotic proteins into 
the cytosol. Of the 3 proteins that comprise the mitochondrial permeability transition pore, cyclophilin D is essential for the permeability transition pore. ${ }^{18}$

Mitochondrial outer membrane permeabilization can occur downstream of death receptortriggered signaling cascades (extrinsic pathway), lysosomal permeabilization, endoplasmic reticulum (ER) stress pathways, or activation of intracellular stress kinases, such as c-jun Nterminal kinase (JNK) (intrinsic pathway) (Figure 1). The Bcl-2 family proteins (Table 1) are best described as mediators of mitochondrial dysfunction. ${ }^{19}$ They are divided into proapoptotic and antiapoptotic proteins. The proapoptotic proteins are structurally divided into multidomain (Bak and Bax) and BH-3 domain only (Bid, Noxa, Puma, Bim, Bmf, Bik, Hrk, and Bad), and Bcl-2, Bcl-xL, A1, and Mcl-1 are the important antiapoptotic proteins. Bax is cytosolic and Bak is located on the mitochondrial membrane; when Bax is activated, it too translocates to mitochondria. These 2 multidomain proapoptotic proteins can, on activation, form pores on the outer mitochondrial membrane, inducing mitochondrial permeabilization. Bax and Bak are either directly or indirectly activated by the BH-3-only proteins. For example, Bid is cytosolic and is activated by caspase 8-mediated cleavage, downstream of death receptor activation, and in turn activates Bax/Bak. The antiapoptotic proteins sequester Bax and Bak, preventing apoptosis. When disabled by excessive binding of BH-3-only proteins, they become overwhelmed releasing Bax and Bak and cell death ensues.

\section{Lysosomes}

When it occurs, lysosomal involvement in cell death is an early event, observed before mitochondrial permeabilization or caspase activation. In general, lysosomes can be activated by the extrinsic or death receptor-mediated pathway or myriad intracellular stimuli, such as free fatty acids, sphingosine, ceramide, reactive oxygen species, photodamage, or lysosomotropic agents (weakly basic amines that can accumulate in lysosomes and raise intravesicular $\mathrm{pH}$ ). ${ }^{20}$ Release of lysosomal proteases (cathepsins) mediates downstream effects. Cathepsin B (one of 11 known human cathepsins) is active at neutral $\mathrm{pH}$ and has been studied in several models of liver injury. Lysosomal permeabilization can result in necrotic cell death or apoptotic cell death. Massive release of cathepsins from total lysosomal permeabilization leads to necrotic cell death. Selective lysosomal permeabilization leads to apoptosis, in some instances independent of caspase activation; however, in liver injury models, caspase activation occurs downstream of lysosomal permeabilization. Lysosomal ultrastructural abnormalities are seen in many chronic liver disorders. Studies utilizing mice deficient in cathepsin B, which develop normally, show that the lysosomal pathway of apoptosis is important in steatohepatitis, cholestatic liver injury, and tumor necrosis factor (TNF)- $\alpha$-mediated liver injury. ${ }^{21-23}$

\section{Endosplamic Reticulum}

ER stress is an active area of research in the pathogenesis of chronic liver injury (Figure 2), although most of the current understanding of the known mediators of the ER stress pathway comes from other experimental systems. The stressed ER exhibits an imbalance between unfolded proteins and mature proteins, activating a series of compensatory responses, collectively termed the unfolded protein response (UPR). ${ }^{24}$ ER stress can also be induced by myriad stimuli, such as calcium depletion, glycosylation inhibition (tunicamycin), UV radiation, and insulin resistance. The ER stress response is a 3-pronged attempt at correcting the accumulation of unfolded proteins, and in situations of inadequate correction or sustained ER stress, it signals cell death. There is a global reduction in protein synthesis, decreasing the amount of newly synthesized proteins that have to enter the ER, and selective induction of a set of genes referred to as UPR target genes. Three membrane sensors have been identified in the ER that function as signal transducers of ER stress: inositol-requiring protein 1 (IRE1), activating transcription factor (ATF) 6 , and protein kinase RNA-like endoplasmic reticulum 
kinase (PERK) (Figure 2). IRE1 activation leads to endoribonucleolytic excision of an intron within X-box binding protein 1 (XBP1) messenger RNA. Uncleaved XBP1 inhibits gene transcription of a set of genes, whereas on its IRE1-mediated processing XBP1 acts as an activator of transcription of the same genes. IRE1 can also signal via JNK; this pathway is implicated in insulin resistance. ATF6 activates UPR target genes. PERK activation leads to phosphorylation of eukaryotic translation initiation factor $2 \alpha$, reducing its activity and thus leading to a global decrease in protein synthesis, and selective translation of ATF4, transcription of C/EBP-homologous protein (CHOP), and activation of nuclear factor $\mathrm{\kappa B}$. ER stress can activate $\mathrm{Bim}$, the potent proapoptotic $\mathrm{BH}-3$-only protein, via $\mathrm{CHOP}$-induced transcription, leading to its increased expression and decreasing its proteasomal degradation. 25 Additionally, CHOP can also increase expression of death receptors. ${ }^{26}$ Thus, based on data in nonliver tissues, the ER stress pathway of cell death can regulate both the intrinsic and extrinsic cell death machinery and is an exciting area of research in liver injury.

\section{Plasma Membrane Death Receptors}

TNF- $\alpha$, Fas ligand (FasL), and tumor necrosis factor-related apoptosis-inducing ligand (TRAIL) are death ligands that signal via binding their cognate receptors, the death receptors. 27 Death receptors belong to the TNF/nerve growth factor superfamily and are essential for death ligand-mediated cell death. The death receptors Fas, tumor necrosis factor receptor 1 (TNFR1), and TRAIL receptors have recognized roles in liver injury. Receptor-ligand binding leads to receptor trimerization and activation of intracellular signaling cascades. The intracellular portion of these proteins contains death domains that recruit adaptor proteins leading to the activation of caspase 8 (an initiator caspase), cleavage of Bid to tBid, which in turn translocates to mitochondria and leads to mitochondrial permeabilization. Also, cell death can occur via TNF- $\alpha$-induced Bid-dependent and TRAIL-induced Bax-dependent lysosomal permeabilization. ${ }^{28}$ While death receptors do not induce ER stress, ER stress-mediated regulation of TRAIL receptor expression has been described. ${ }^{26}$

\section{Fas}

Hepatocytes, cholangiocytes, sinusoidal endothelial cells, stellate cells, and Kupffer cells express Fas (CD95/Apo-1). ${ }^{29-31}$ Fas is activated on binding with membrane-bound FasL or soluble FasL. FasL is expressed on cytotoxic T lymphocytes and natural killer (NK) cells. 32 Fas is important in hepatic health and disease. Mice genetically deficient in Fas exhibit hepatic hyperplasia. ${ }^{33}$ Fas-induced cell death leads to removal of unwanted hepatocytes, such as virusinfected hepatocytes and cancer cells, by NK cells, NK T cells, and T lymphocytes. ${ }^{34-36}$ The exquisite sensitivity of the liver to Fas was shown by the induction of fulminant hepatic failure on injection of an Fas agonistic antibody in mice in $1993 .{ }^{1}$ Furthermore, in a series of elegant experiments, it was shown that this toxicity is regulated by the Bcl-2 family proteins, prevented by Bcl-2, 37 and dependent on the proapoptotic protein Bid. ${ }^{38}$ Significant elevations of soluble FasL occur in patients with acute liver failure, such as drug-induced liver injury or acetaminophen-induced liver injury. 39,40 FasL and Fas receptor expression is up-regulated in many chronic liver diseases. $4,35,41,42$ Fas signaling cascades are shown in Figure 3.

\section{TNF- $\alpha$}

TNFR1 and TNFR2 are both expressed on hepatocytes, although only TNFR1 expresses a death domain and executes the apoptotic program. ${ }^{43}$ TNFR1 can activate both prosurvival and proapoptotic signals. ${ }^{44,45}$ TNF- $\alpha /$ TNFR1 signaling occurs in 2 steps (Figure 4); immediate recruitment of TNFR-associated protein (TRAF2) and receptor interacting protein leads to activation of nuclear factor $\kappa \mathrm{B}$ and transcriptional activation of prosurvival genes (eg, $\mathrm{Bcl}-\mathrm{xL}$, A1, XIAP, and cFLIP). ${ }^{46}$ Apoptotic signaling occurs subsequently via the adaptor protein TNFR-associated death domain (TRADD) mediated caspase 8/Fas-associated death domain 
(FADD) activation in a receptor-initiated, albeit receptor-independent, cytosolic complex. In this dual signaling process, prosurvival signals predominate; indeed, to unmask the proapoptotic signaling, in experimental models inhibitors of protein synthesis are used. The biological role is even more complex because in addition to its role as an inflammatory cytokine, TNF- $\alpha$ also mediates caspase-independent death via formation of reactive oxygen species. Receptor interacting protein 1 is recruited to TNFR1 and activates Nox 1 reduced nicotinamide adenine dinucleotide phosphate oxidase, leading to reactive oxygen species formation and sustained activation of JNK leading to necrotic cell death. ${ }^{47}$ Further studies are needed to elucidate the role of this pathway in liver diseases. While cultured primary hepatocytes are resistant to TNF- $\alpha$ toxicity, diseased hepatocytes can be sensitized to its toxicity. Very recently, the loss of cellular inhibitors of apoptosis proteins 1 and 2 has been shown to sensitize cancer cells to TNF- $\alpha$-mediated cytotoxicity. ${ }^{48}$ The effect of liver diseases on expression of cellular inhibitors of apoptosis proteins 1 and 2 is an interesting area of study.

\section{TRAIL}

TRAIL receptor 1 (death receptor 4) and TRAIL receptor 2 (death receptor 5/killer/TRICK2) are of intense interest and emerging significance in the pathogenesis of chronic liver diseases. 49 TRAIL receptors 1 and 2 can induce apoptosis via caspase activation, similar to Fas. Death receptor 3 (Apo-3/TRAMP/WSL-1/LARD) and death receptor 6 are incomplete receptors and cannot stimulate apoptotic signaling. While some controversy exists, the majority agrees that TRAIL is harmless to normal human hepatocytes. ${ }^{50}$ Emerging data point to the sensitization of diseased hepatocytes to TRAIL-mediated apoptosis in several models of hepatitis, both experimental and human chronic viral hepatitis as well as nonalcoholic fatty liver disease. ${ }^{51}$, 52

\section{JNK}

Membrane/organelle-initiated cytotoxic signaling pathways often converge on JNK; therefore, a brief discussion of JNK is relevant to all of the above mechanisms of cell death. Of 3 known mammalian JNK genes, 2 are expressed in the liver: JNK1 and JNK2. 53 Both can be activated by death receptor and ER stress pathways of apoptosis and may also be the pathway of caspaseindependent reactive oxygen species-mediated cell death. While transient JNK activation is prosurvival, sustained JNK activation leads to cell death. This can occur via modulation of Bcl-2 family proteins, with subsequent mitochondrial permeabilization. For example, JNK can phosphorylate Bim, resulting in its activation and triggering mitochondrial dysfunction, 54 or lead to caspase 8 activation, Bid cleavage, and mitochondrial cytochrome $c$ release. 55

Sustained JNK1 activation can promote degradation of cFLIP (an endogenous inhibitor of death receptor signaling), thereby promoting cell death by TNFR1, Fas, or TRAIL receptor 1/ TRAIL receptor $2.56 \mathrm{JNK}$ can also promote transcription-dependent cell death by activating the transcription factor AP-1. Both JNK1 and JNK2 have been implicated in liver injury. In dietary obesity, JNK1 plays a predominant role ${ }^{57}$; however, in free fatty acid-based cellular models of hepatocyte lipoapoptosis and toxin-mediated TNF-dependent liver injury, JNK2 plays a predominant role. ${ }^{55,58}$ In acetaminophen-induced acute liver injury JNK2 is predominant, although both JNK1 and JNK2 partly mediate its toxicity. ${ }^{59}$ Thus, JNK plays a pivotal role in many models of cell death.

\section{Innate Immune System}

The innate immune system is mentioned briefly because inflammation is an inseparable component of both acute and chronic liver injury. The readers are referred elsewhere for recent excellent reviews. ${ }^{60}$ Suffice it to say that the liver, with its large population of Kupffer cells (tissue resident macrophages), dendritic cells, NK cells, and NK T cells, acts as an "immune organ" and has the unique milieu of close interaction between these immune cells and the 
nonimmune cells of the liver. The cells of the innate immune system are not only the sources of inflammatory cytokines, especially TNF- $\alpha$, but may well be the source of FasL and TRAIL in diseased livers. Indeed, it is the cells of the innate immune system that express the death ligands for death receptor-mediated liver injury. One of the more interesting features of liver injury in this context is the expression of stress ligands for the NK and NK T-cell receptor NKG2D; stressed hepatocytes may very well "invite" their destruction. ${ }^{61}$

\section{Disease-Specific Mechanisms}

\section{Acute Liver Injury}

Acetaminophen-induced acute liver injury is the leading cause of acute liver failure in the United States. Acetaminophen is metabolized to glucuronide and sulfate conjugates and excreted, and to a smaller extent ( $<5 \%)$ it is metabolized via cytochrome P450 2E1 to $N$-acetylp-benzoquinoneimine (NAPQI). NAPQI undergoes glutathione conjugation and is safely excreted. In acetaminophen-induced acute liver injury, glutathione depletion occurs and NAPQI accumulates within hepatocytes, presumably leading to irreversible binding to cellular and mitochondrial thiol proteins and mitochondrial permeabilization and cell death. This is the rationale for utilization of $\mathrm{N}$-acetyl cysteine as an antidote. If given in a timely manner (within 16 hours of drug ingestion) it repletes cellular thiol stores, promoting NAPQI conjugation and excretion. However, if not administered early enough, the metabolism of acetaminophen is followed by an acute inflammatory response and liver cell death. Recently, several advances have been made into the mechanisms of acetaminophen-induced cytotoxicity. JNK activation and Bax translocation to mitochondria occur in models of acetaminophen toxicity, before onset of cell death. ${ }^{59}$ Inhibition of JNK, both pharmacologically and genetically, results in improved survival, lower TNF- $\alpha$ Fas, and FasL levels, and cell death. Even delayed JNK inhibition was effective in reducing cell death, unlike $N$-acetyl cysteine. ${ }^{62}$ Furthermore, involvement of the innate immune system in acetaminophen-induced liver injury was shown by NK and NK Tcell depletion that abrogates acetaminophen-induced hepatotoxicity. ${ }^{63}$

Elevated circulating levels of Fas, TNF- $\alpha$, and TNFR are found in patients with acetaminopheninduced acute liver injury and fulminant hepatic failure of other causes. ${ }^{39,40,64}$ In addition to Fas and TNF- $\alpha$, intrahepatic caspase activation, intrahepatic M30 immunostaining, and circulating levels of M30 are increased in patients with fulminant hepatic failure. Indeed, high levels of apoptosis (as measured by circulating M30) correlate with need for organ transplantation or death, and lower levels of apoptosis were found in spontaneous survivors. Whether the cytokine/death ligand balance in acute liver injury can be manipulated for therapeutic gain remains to be seen. Theoretically, inhibition of the innate immune response, Fas signaling, or JNK-induced apoptosis may be of benefit in decreasing massive hepatocyte apoptosis. ${ }^{65,66}$

\section{Cholestatic Liver Injury}

Cholestatic liver injury is a descriptive term applied to liver injury occurring in the presence of bile flow impairment. It is characterized by elevated hepatocellular levels of toxic bile acids. Mechanisms of bile salt-induced liver injury have been elucidated using in vitro models as well as the bile duct-ligated mouse model. Bile salt toxicity correlates with their lipophilicity, conjugation state, and concentration, occurring well below the critical micellar concentration required for direct detergent activity; glycine-conjugated chenodeoxycholic acid is more toxic than the taurine-conjugated chenodeoxycholic acid. Elegant in vitro and in vivo studies have shown that hepatocyte apoptosis is a prominent feature of cholestatic liver diseases. ${ }^{67}$ In cell culture models, glycine-conjugated chenodeoxycholic acid leads to Fas-induced cell death.

68 It can do so even in the absence of FasL by increasing cell surface trafficking of Fas and spontaneous oligomerization. ${ }^{69}$ This ligand-independent oligomerization occurs in an 
epidermal growth factor receptor-dependent fashion involving Yes kinase and culminating in the phosphorylation of Fas. ${ }^{70}$ Fas-deficient (lpr) mice show attenuated, but not absent, hepatocyte apoptosis following bile duct ligation. ${ }^{67}$ This led to the demonstration that glycineconjugated chenodeoxycholic acid also up-regulates TRAIL receptor 2 expression and sensitizes hepatocytes to TRAIL-induced apoptosis. ${ }^{71,72}$ Glycine-conjugated chenodeoxycholic acid-induced Fas-dependent and Fas-independent apoptosis can be blocked by inhibiting Bid expression. ${ }^{73}$ This also prevents glycine-conjugated chenodeoxycholic acidinduced mitochondrial permeabilization and cytochrome $c$ release.

Fas-deficient mice also display reduced fibrosis following bile duct ligation, pointing to a link between hepatocyte apoptosis and fibrogenesis. ${ }^{74}$ Caspase inhibition with IDN-6556 (a commercially available, pan-caspase inhibitor), also led to attenuation of hepatocyte apoptosis and liver inflammation and was antifibrogenic. ${ }^{75}$ Further studies promoting stellate cell apoptosis in these models have also shown decreased fibrosis. ${ }^{76}$ Thus, in cholestatic disorders, apoptosis can be modulated in 2 ways for therapeutic gain: inhibition of hepatocyte apoptosis with the goal of decreasing inflammation and fibrosis and promotion of stellate cell apoptosis with the goal of halting fibrogenesis. The toxic bile salt sodium deoxycholate can activate the ER stress pathway in an in vitro model. ${ }^{77}$ This is also observed in vivo; in transgenic mice overexpressing $\alpha_{1}$-antitrypsin $\mathrm{Z}$ protein in the $\mathrm{ER}$, cholestatic injury is associated with activation of the ER stress pathway, although ER stress pathway activation is not observed in wild-type bile duct-ligated mice. 78

\section{Chronic Viral Hepatitis}

Chronic hepatitis $\mathrm{C}(\mathrm{HCV})$ is the most common cause of end-stage liver disease and the leading indication for liver transplantation in the United States. HCV causes persistent infection and fibrosis. The mechanisms that lead to the establishment of immune evasion and persistent infection are complex and beyond the scope of this review. Based on the paradigm of hepatocyte apoptosis begetting fibrosis as an injury response, up-regulation of hepatocyte apoptosis in chronic hepatitis $\mathrm{C}$ would be expected. Indeed, there is ongoing, low-grade, Fasmediated apoptosis that correlates with the severity of inflammation. ${ }^{79}$ Fas expression is enhanced on infected hepatocytes, leading to HCV-specific T cell-mediated apoptosis via expression of FasL. ${ }^{80,81}$ Circulating levels of soluble FasL are elevated in HCV infection and correlate with serum alanine aminotransferase level and histologic grade. ${ }^{35}$ The cytokeratin 18 neoantigen (M30) is also elevated in patients with chronic hepatitis C. ${ }^{82}$ Even in patients who have normal serum alanine aminotransferase levels, M30 levels are elevated, reflecting ongoing hepatocyte apoptosis; the highest levels occur in patients with cirrhosis. This surrogate marker of apoptosis needs further validation and may eliminate the need for repeated liver biopsies.

Hepatitis C viral proteins regulate apoptosis. Both proapoptotic and antiapoptotic actions have been described. In different cellular models, the HCV core protein can sensitize TRAILresistant Huh7 cells to TRAIL-induced apoptosis ${ }^{83}$; it can bind to the death domain of TNFR1 and sensitize to TNF- $\alpha$-induced apoptosis by increasing expression of FADD ${ }^{84}$ and sensitize to Fas-induced apoptosis in HepG2 cells. ${ }^{85}$ NS3 protein can promote activation of caspase 8, sensitizing to Fas-induced apoptosis. ${ }^{86}$ Synergistic Fas-mediated apoptosis occurs with alcohol consumption in hepatitis $\mathrm{C}$ and is associated with increased Fas levels. ${ }^{79}$ Murine hepatocytes that express envelope protein 1 (E1) and envelope protein 2 (E2) can increase apoptosis of activated T cells, providing a mechanism for immune escape in chronic infection. 87

Hepatitis B virus (HBV) infection also regulates the apoptotic machinery to its benefit, establishing persistent infection and evading the immune system. Similar to chronic HCV infection, chronic HBV infection is also characterized by low levels of hepatocyte apoptosis. 
Liver injury is triggered by host immune response to viral protein expressing hepatocytes, because the virus is non-cytopathic. Serum Fas and hepatic TNFR1, TNF- $\alpha$, and Fas expression are enhanced in chronic HBV infection and correlate with histologic activity 36,45 ; in patients with fulminant hepatic failure due to HBV, Fas-expressing infiltrating lymphocytes were shown in areas of apoptotic hepatocytes. ${ }^{40}$ Chronic HBV infection is characterized by periodic flares. NK cell TRAIL expression increases in temporal correlation with serum alanine aminotransferase levels during flares, and TRAIL receptor 2 is found to be up-regulated in liver samples from patients with chronic HBV. ${ }^{51}$ In another study, Bax protein and messenger RNA were up-regulated in hepatocytes, and Bax expression positively correlated with the number of apoptotic nuclei ${ }^{88}$; hepatocyte sensitization to TRAIL toxicity was also Bax dependent. ${ }^{89}$ In experimental models, HBx protein can up-regulate TRAIL receptor 1 expression, leading to TRAIL-mediated apoptosis. ${ }^{90}$

\section{Alcoholic Steatohepatitis}

Hepatocyte steatosis, ballooning, apoptosis, and a lobular inflammatory infiltrate are the characteristic histologic features of alcoholic steatohepatitis. In the absence of advanced fibrosis, these changes are reversible on cessation of alcohol consumption. In experimental models, ethanol produces characteristic changes of mitochondrial and microsomal dysfunction, 91,92 oxidative stress, ${ }^{93}$ Bax translocation to mitochondria, and mitochondrial permeability transition leading to cytochrome $c$ release and caspase activation. ${ }^{94}$ Conversely, antioxidants, inhibition of mitochondrial permeability transition, or inhibition of caspases prevents acute ethanol-induced apoptosis. Ethanol induces cytochrome P450 2E1 in hepatocytes, further promoting formation of reactive oxygen species. Ethanol ingestion also leads to activation of Kupffer cells. ${ }^{95}$ Activated Kupffer cells secrete multiple inflammatory cytokines, such as TNF- $\alpha$, interleukin- 6 , transforming growth factor $\beta 1$, that further promote liver inflammation, and inactivation of Kupffer cells prevents ethanol-induced liver injury. The importance of TNF- $\alpha$ in the pathogenesis of alcoholic steatohepatitis is well characterized. ${ }^{96}$ It mediates both hepatocyte apoptosis and hepatic inflammation. Circulating levels of TNF- $\alpha$ and TNFR1 are elevated in alcoholic steatohepatitis, and the latter correlates with 3-month mortality 97,98 ; hepatic expression of TNFR is enhanced in chronic ethanol ingestion, ${ }^{3}$ and genetic studies in mice show that TNFR1 is essential for alcohol-induced liver injury. ${ }^{96}$ In another study, TNFR1 only partially mediated ethanol-induced liver injury in mice, suggesting a TNF- $\alpha$-independent role for the ER stress pathway (vide infra). ${ }^{99}$ TNF- $\alpha$ neutralization decreases hepatic injury and inflammation in experimental models. ${ }^{100}$ While data on infliximab are conflicting, initial studies using etanercept, a TNF-neutralizing antibody, have shown its safety in humans, and larger studies are under way. ${ }^{101}$

In the proinflammatory cytokine milieu of alcoholic steatohepatitis, the mode of cell death of hepatocytes is apoptotic. ${ }^{5}$ Apoptosis correlates with bilirubin level, aspartate aminotransferase level, inflammation, and Maddrey score, a prognostic indicator in acute alcoholic hepatitis. Hepatic Fas receptor expression is enhanced in alcoholic steatohepatitis, as are circulating levels of Fas, FasL, and TNF- $\alpha .{ }^{3}$ Apoptotic hepatocytes colocalize with infiltrating neutrophils, suggesting that the characteristic inflammatory response partly occurs secondary to hepatocyte apoptosis and partly due to the direct activation of Kupffer cells by ethanol leading to cytokine production. Stellate cells are also regulated in a paracrine manner by acetaldehyde and reactive oxygen species, produced by the metabolism of ethanol in surrounding hepatocytes. ${ }^{102}$ One area of active research is ER stress. Acetal-dehyde, an ethanol metabolite, induces ER stress in cell culture systems. ${ }^{103}$ Mitochondrial dysfunction occurs as a consequence of ER stress. In animal models, ethanol induces a CHOP-dependent apoptosis. ${ }^{104}$ Wild-type mice on ethanol feeding up-regulate cathepsin B and GADD45 and simultaneously down-regulate Bcl-xL, leading to several-fold enhanced apoptosis. However, mice that lack CHOP show the opposite gene expression regulation, decreased cathepsin B, 
decreased GADD45, increased Bcl-xL, and no apoptosis. Inflammation and some other markers of ER stress are observed in both groups of mice. Thus, CHOP is a significant mediator of ER stress-induced apoptosis in liver disease secondary to alcohol. Fibrogenesis in this model and the importance of CHOP in human alcoholic liver disease needs further study. Significant advances have been made in ethanol-mediated hepatocyte apoptosis and pathways of liver injury; however, the characteristics of the subset of individuals who develop progressive liver injury and fibrosis from chronic ethanol ingestion are still not clear. Differences in CHOP regulation could be one potential explanation.

\section{Nonalcoholic Steatohepatitis}

Nonalcoholic steatohepatitis shares histologic similarities with alcoholic steatohepatitis ${ }^{4}$; however, the candidate mediators of liver injury are distinct and potentially include alterations in circulating cytokines, adipokines, and free fatty acids. Elevated circulating (serum) free fatty acid levels occur in patients with nonalcoholic steatohepatitis. ${ }^{105}$ Liver triglyceride is derived primarily from circulating free fatty acids, derived from adipose tissue lipolysis. ${ }^{106}$ In insulin resistance, adipose tissue lipolysis and liver triglyceride deposition are enhanced.

Comprehensive lipidomic profiling of human subjects with nonalcoholic fatty liver disease and nonalcoholic steatohepatitis have recently been reported. ${ }^{107}$ Several interesting observations can be made on the basis of this profiling. The first confirms that liver triacyl glycerol and diacyl glycerol levels are significantly increased in patients with nonalcoholic fatty liver disease and nonalcoholic steatohepatitis. The second observation pertains to hepatic free fatty acids. These are unchanged across the spectrum from controls to nonalcoholic fatty liver disease to nonalcoholic steatohepatitis, although careful analysis of the triacyl glycerol composition shows increased saturated fatty acid (particularly palmitic acid) and monounsaturated fatty acid levels (oleic acid in both triacyl glycerol and diacyl glycerol); simultaneous serum free fatty acid concentrations were not measured. Elevated circulating palmitic acid and oleic acid levels in previous studies and their subsequent availability for formation of triglyceride are consistent with the observed increase in their esterified forms in the liver. It also confirms the belief that free fatty acid toxicity is mediated by pathways independent of their availability for formation of triglyceride (vide infra) and that triglyceride accumulation is a surrogate marker for the very metabolic abnormalities that result in elevated free fatty acid levels.

Free fatty acid-induced lipoapoptosis has been shown in many cell types in the metabolic syndrome, including pancreatic beta cells, vascular endothelial cells, cardiac myocytes, and hepatocytes. ${ }^{58,108}$ In hepatocytes, free fatty acids can activate the lysosomal pathway of cell death, sensitizing cells to TNF- $\alpha$ toxicity. ${ }^{23}$ Furthermore, free fatty acids induce a JNKdependent lipoapoptosis, which is mediated by intracellular Bim levels and Bax activation, leading to mitochondrial permeabilization, cytochrome $c$ release, and caspase activation. 58 Saturated fatty acids induce Bim expression via a FoxO3A-dependent pathway. ${ }^{109}$ JNK activation correlates with observed toxicity for each free fatty acid tested, and saturated free fatty acids lead to sustained JNK activation and are more toxic than monounsaturated free fatty acids. Even minimally toxic oleic acid sensitizes hepatocytes to TRAIL-mediated apoptosis. 52 The ER stress pathway is also activated by saturated free fatty acids in pancreatic beta cells, and its role in steatohepatitis merits further investigation. ${ }^{110}$

In keeping with the in vitro observations, steatotic livers are sensitized to Fas-mediated and TRAIL-mediated apoptosis. ${ }^{50,111}$ In human biopsy samples, hepatocyte apoptosis correlates with inflammation and fibrosis. ${ }^{4}$ Elevated Fas, TNF receptor, and TRAIL receptor 2 expression is seen in liver biopsy samples. Circulating caspase target M30 is also elevated in patients with nonalcoholic steatohepatitis and serum levels correlate with hepatic levels of the same, again offering a noninvasive means of measuring apoptosis. ${ }^{14}$ Sensitization to death ligands may 
occur independently of JNK activation in vivo, which is known to mediate insulin resistance and liver injury in models of dietary obesity. ${ }^{57}$

\section{Fibrogenesis}

Hepatic fibrosis is the hallmark of chronic liver injury. Sustained hepatocyte losses could conceivably be corrected by repopulation were it not for the development of fibrosis. Hepatic stellate cells remain quiescent in health and are activated in response to injury. Activated stellate cells are recognized as fibrogenic and lead to the deposition of collagen type 1. Kupffer cells, resident liver macrophages, are activated by engulfment of apoptotic hepatocytes; this leads to removal of dead cells from the liver. Furthermore, activated Kupffer cells secrete inflammatory cytokines, linking apoptosis in the liver to inflammation. Similarly, apoptotic bodies can be engulfed by stellate cells, leading to their activation and enhanced expression of $\alpha$-smooth muscle actin, transforming growth factor $\beta$, and collagen type I. ${ }^{112}$ In vivo, inhibition of hepatocyte apoptosis, such as in the Fas-deficient bile duct-ligated mouse, also leads to less fibrosis. ${ }^{74}$ This phenomenon could result from a direct interaction between apoptotic hepatocytes and stellate cells in vivo or an indirect effect of decreased Kupffer cell activation and inflammation. Stellate cells undergo apoptosis during the resolution of liver injury. ${ }^{113}$ In conditions of ongoing liver injury, selective induction of stellate cell apoptosis can dissociate hepatocyte apoptosis from fibrogenesis. ${ }^{76}$ Activated stellate cells also express enhanced levels of TRAIL receptor 2 and are susceptible to TRAIL-mediated apoptosis. ${ }^{114}$ A model of the central role of hepatocyte apoptosis in liver injury and fibrosis is depicted in Figure 5.

\section{Therapeutic Implications}

Advances in mechanistic understanding impart clinical significance if therapeutic interventions can be derived from them. In this context, cell death pathways present many potential therapeutic targets. ${ }^{115}$ Some recent exciting developments are discussed here. The monoclonal M30 antibody that recognizes a caspase-generated cytokeratin 18 neoantigen is an excellent example of a clinical application. This test is reliable, easy, and accurate in many disease models. Studies in larger validation cohorts are needed before it can replace more invasive testing. It is promising because highest levels were found in cirrhotic patients in one study, and in another study it could reliably differentiate nonalcoholic fatty liver disease from nonalcoholic steatohepatitis. ${ }^{14,82}$ Inhibition of the mitochondrial permeability transition utilizing $N$-methyl-4-isoleucine cyclosporine (NIM811) or minocycline led to a decrease in liver injury and improved graft survival in experimental liver transplantation; the former also improved regeneration of small-for-size liver grafts. ${ }^{116}$ Pan-caspase inhibitor, IDN 6556, showed promise in preclinical studies by inhibiting hepatocyte apoptosis, decreasing inflammation and fibrosis. ${ }^{117}$ In a small phase 2 clinical trial, it lowered serum aminotransferase activity following oral administration for 2 weeks. Larger and longer studies, especially with incorporation of other measures of injury and fibrosis, are necessary. Ursodeoxycholic acid is commonly used in the treatment of cholestatic liver disorders. Inhibition of apoptosis in hepatocytes partly mediates the salutary effects of ursodeoxycholic acid. ${ }^{118,119}$ TRAIL receptor antibodies are being investigated in cancer therapy; emerging data indicate that in chronic liver disease (HBV, HCV, nonalcoholic fatty liver disease), hepatocytes are sensitized to TRAIL-induced apoptosis, a potential toxicity that may limit their therapeutic potential. ${ }^{50} \mathrm{JNK}$ inhibitors are in clinical development and based on preclinical studies may be lifesaving in acetaminophen-induced acute liver failure and beneficial in nonalcoholic fatty liver disease. Of the BH-3-only proteins, Bim has been studied in liver disease; these are also attractive potential targets. 


\section{Biographies}

Harmeet Malhi

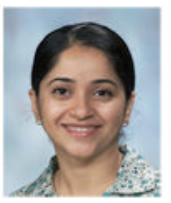

Gregory J. Gores

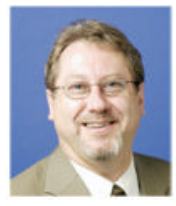

\section{Abbreviations used in this paper}

ATF, activating transcription factor

CHOP, C/EBP-homologous protein

$\mathrm{ER}$, endoplasmic reticulum

FADD, Fas-associated death domain

FasL, Fas ligand

IRE1, inositol-requiring protein 1

JNK, c-jun N-terminal kinase

NAPQI, $N$-acetyl-p-benzoqui-noneimine

NK, natural killer

PERK, protein kinase RNA-like endoplasmic reticulum kinase

TNF, tumor necrosis factor

TNFR, tumor necrosis factor receptor

TRAIL, tumor necrosis factor-related apoptosis inducing ligand receptor

UPR, unfolded protein response

$\mathrm{XBP} 1, \mathrm{X}$-box binding protein 1

\section{References}

1. Ogasawara J, Watanabe-Fukunaga R, Adachi M, et al. Lethal effect of the anti-Fas antibody in mice. Nature 1993;364:806-809. [PubMed: 7689176]

2. Matsumura H, Shimizu Y, Ohsawa Y, et al. Necrotic death pathway in Fas receptor signaling. J Cell Biol 2000;151:1247-1256. [PubMed: 11121439]

3. Ribeiro PS, Cortez-Pinto H, Sola S, et al. Hepatocyte apoptosis, expression of death receptors, and activation of NF-kappaB in the liver of nonalcoholic and alcoholic steatohepatitis patients. Am J Gastroenterol 2004;99:1708-1717. [PubMed: 15330907]

4. Feldstein AE, Canbay A, Angulo P, et al. Hepatocyte apoptosis and fas expression are prominent features of human nonalcoholic steatohepatitis. Gastroenterology 2003;125:437-443. [PubMed: 12891546]

5. Natori S, Rust C, Stadheim LM, et al. Hepatocyte apoptosis is a pathologic feature of human alcoholic hepatitis. J Hepatol 2001;34:248-253. [PubMed: 11281553]

6. Vieira WT, Gayotto LC, de Lima CP, et al. Histopathology of the human liver in yellow fever with special emphasis on the diagnostic role of the Councilman body. Histopathology 1983;7:195-208. [PubMed: 6303935] 
7. Natori S, Higuchi H, Contreras P, et al. The caspase inhibitor IDN-6556 prevents caspase activation and apoptosis in sinusoidal endothelial cells during liver preservation injury. Liver Transpl 2003;9:278-284. [PubMed: 12619025]

8. Papakyriakou P, Tzardi M, Valatas V, et al. Apoptosis and apoptosis related proteins in chronic viral liver disease. Apoptosis 2002;7:133-141. [PubMed: 11865197]

9. Natori S, Selzner M, Valentino KL, et al. Apoptosis of sinusoidal endothelial cells occurs during liver preservation injury by a caspase-dependent mechanism. Transplantation 1999;68:89-96. [PubMed: 10428274]

10. Kohli V, Selzner M, Madden JF, et al. Endothelial cell and hepatocyte deaths occur by apoptosis after ischemia-reperfusion injury in the rat liver. Transplantation 1999;67:1099-1105. [PubMed: 10232558]

11. Hetz H, Hoetzenecker K, Hacker S, et al. Caspase-cleaved cytokeratin 18 and $20 \mathrm{~S}$ proteasome in liver degeneration. J Clin Lab Anal 2007;21:277-281. [PubMed: 17847110]

12. Yagmur E, Trautwein C, Leers MP, et al. Elevated apoptosis-associated cytokeratin 18 fragments (CK18Asp386) in serum of patients with chronic liver diseases indicate hepatic and biliary inflammation. Clin Biochem 2007;40:651-655. [PubMed: 17306787]

13. Luft T, Conzelmann M, Benner A, et al. Serum cytokeratin-18 fragments as quantitative markers of epithelial apoptosis in liver and intestinal graft-versus-host disease. Blood 2007;110:4535-4542. [PubMed: 17702900]

14. Wieckowska A, Zein NN, Yerian LM, et al. In vivo assessment of liver cell apoptosis as a novel biomarker of disease severity in nonalcoholic fatty liver disease. Hepatology 2006;44:27-33. [PubMed: 16799979]

15. Malhi H, Gores GJ, Lemasters JJ. Apoptosis and necrosis in the liver: a tale of two deaths? Hepatology 2006;43:S31-S44. [PubMed: 16447272]

16. Green DR, Kroemer G. The pathophysiology of mitochondrial cell death. Science 2004;305:626629. [PubMed: 15286356]

17. Green DR. Apoptotic pathways: ten minutes to dead. Cell 2005;121:671-674. [PubMed: 15935754]

18. Baines CP, Kaiser RA, Purcell NH, et al. Loss of cyclophilin D reveals a critical role for mitochondrial permeability transition in cell death. Nature 2005;434:658-662. [PubMed: 15800627]

19. Cory S, Huang DC, Adams JM. The Bcl-2 family: roles in cell survival and oncogenesis. Oncogene 2003;22:8590-8607. [PubMed: 14634621]

20. Guicciardi ME, Leist M, Gores GJ. Lysosomes in cell death. Oncogene 2004;23:2881-2890. [PubMed: 15077151]

21. Kyaw A, Aung T, Htut T, et al. Lysosomal enzyme activities in normals and in patients with chronic liver diseases. Clin Chim Acta 1983;131:317-323. [PubMed: 6883725]

22. Guicciardi ME, Deussing J, Miyoshi H, et al. Cathepsin B contributes to TNF-alpha-mediated hepatocyte apoptosis by promoting mitochondrial release of cytochrome c. J Clin Invest 2000;106:1127-1137. [PubMed: 11067865]

23. Feldstein AE, Werneburg NW, Canbay A, et al. Free fatty acids promote hepatic lipotoxicity by stimulating TNF-alpha expression via a lysosomal pathway. Hepatology 2004;40:185-194. [PubMed: 15239102]

24. Ron D, Walter P. Signal integration in the endoplasmic reticulum unfolded protein response. Nat Rev Mol Cell Biol 2007;8:519-529. [PubMed: 17565364]

25. Puthalakath H, O'Reilly LA, Gunn P, et al. ER stress triggers apoptosis by activating BH3-only protein Bim. Cell 2007;129:1337-1349. [PubMed: 17604722]

26. He Q, Luo X, Jin W, et al. Celecoxib and a novel COX-2 inhibitor ON09310 upregulate death receptor 5 expression via GADD153/CHOP. Oncogene. 2007 Oct 29; epub ahead of print

27. Guicciardi, ME.; Gores, GJ. The death receptor family and the extrinsic pathway. In: Yin, X-M.; Dong, Z., editors. Essentials of apoptosis: a guide for basic and clinical research. Totowa, NJ: Humana Press Inc; 2003. p. 67-84.

28. Werneburg NW, Guicciardi ME, Bronk SF, et al. Tumor necrosis factor-related apoptosis-inducing ligand activates a lysosomal pathway of apoptosis that is regulated by Bcl-2 proteins. J Biol Chem 2007;282:28960-28970. [PubMed: 17686764] 
29. Muschen M, Warskulat U, Douillard P, et al. Regulation of CD95 (APO-1/Fas) receptor and ligand expression by lipopolysaccharide and dexamethasone in parenchymal and nonparenchymal rat liver cells. Hepatology 1998;27:200-208. [PubMed: 9425938]

30. Cardier JE, Schulte T, Kammer H, et al. Fas (CD95, APO-1) antigen expression and function in murine liver endothelial cells: implications for the regulation of apoptosis in liver endothelial cells. FASEB J 1999;13:1950-1960. [PubMed: 10544178]

31. Ueno Y, Ishii M, Yahagi K, et al. Fas-mediated cholangiopathy in the murine model of graft versus host disease. Hepatology 2000;31:966-974. [PubMed: 10733554]

32. Berke G. The CTL's kiss of death. Cell 1995;81:9-12. [PubMed: 7536631]

33. Adachi M, Suematsu S, Suda T, et al. Enhanced and accelerated lymphoproliferation in Fas-null mice. Proc Natl Acad Sci U S A 1996;93:2131-2136. [PubMed: 8700897]

34. Mochizuki K, Hayashi N, Hiramatsu N, et al. Fas antigen expression in liver tissues of patients with chronic hepatitis B. J Hepatol 1996;24:1-7. [PubMed: 8834017]

35. Lapinski TW, Kowalczuk O, Prokopowicz D, et al. Serum concentration of sFas and sFasL in healthy HBsAg carriers, chronic viral hepatitis B and C patients. World J Gastroenterol 2004;10:3650-3653. [PubMed: 15534924]

36. Song le H, Binh VQ, Duy DN, et al. Variations in the serum concentrations of soluble Fas and soluble Fas ligand in Viet-namese patients infected with hepatitis B virus. J Med Virol 2004;73:244-249. [PubMed: 15122799]

37. Lacronique V, Mignon A, Fabre M, et al. Bcl-2 protects from lethal hepatic apoptosis induced by an anti-Fas antibody in mice. Nat Med 1996;2:80-86. [PubMed: 8564847]

38. Yin XM, Wang K, Gross A, et al. Bid-deficient mice are resistant to Fas-induced hepatocellular apoptosis. Nature 1999;400:886-891. [PubMed: 10476969]

39. Rutherford AE, Hynan LS, Borges CB, et al. Serum apoptosis markers in acute liver failure: a pilot study. Clin Gastroenterol Hepatol 2007;5:1477-1483. [PubMed: 17967565]

40. Ryo K, Kamogawa Y, Ikeda I, et al. Significance of Fas antigen-mediated apoptosis in human fulminant hepatic failure. Am J Gastroenterol 2000;95:2047-2055. [PubMed: 10950056]

41. Kiyici M, Gurel S, Budak F, et al. Fas antigen (CD95) expression and apoptosis in hepatocytes of patients with chronic viral hepatitis. Eur J Gastroenterol Hepatol 2003;15:1079-1084. [PubMed: 14501615]

42. Taieb J, Mathurin P, Poynard T, et al. Raised plasma soluble Fas and Fas-ligand in alcoholic liver disease. Lancet 1998;351:1930-1931. [PubMed: 9654266]

43. Hsu H, Xiong J, Goeddel DV. The TNF receptor 1-associated protein TRADD signals cell death and NF-kappa B activation. Cell 1995;81:495-504. [PubMed: 7758105]

44. Yamada Y, Webber EM, Kirillova I, et al. Analysis of liver regeneration in mice lacking type 1 or type 2 tumor necrosis factor receptor: requirement for type 1 but not type 2 receptor. Hepatology 1998;28:959-970. [PubMed: 9755232]

45. Fang JW, Shen WW, Meager A, et al. Activation of the tumor necrosis factor-alpha system in the liver in chronic hepatitis B virus infection. Am J Gastroenterol 1996;91:748-753. [PubMed: 8677942]

46. Micheau O, Tschopp J. Induction of TNF receptor I-mediated apoptosis via two sequential signaling complexes. Cell 2003;114:181-190. [PubMed: 12887920]

47. Kim YS, Morgan MJ, Choksi S, et al. TNF-induced activation of the Nox1 NADPH oxidase and its role in the induction of necrotic cell death. Mol Cell 2007;26:675-687. [PubMed: 17560373]

48. Varfolomeev E, Blankenship JW, Wayson SM, et al. IAP antagonists induce autoubiquitination of c-IAPs, NF-kappaB activation, and TNFalpha-dependent apoptosis. Cell 2007;131:669-681. [PubMed: 18022362]

49. Schneider P, Thome M, Burns K, et al. TRAIL receptors 1 (DR4) and 2 (DR5) signal FADDdependent apoptosis and activate NF-kappaB. Immunity 1997;7:831-836. [PubMed: 9430228]

50. Volkmann X, Fischer U, Bahr MJ, et al. Increased hepatotoxicity of tumor necrosis factor-related apoptosis-inducing ligand in diseased human liver. Hepatology 2007;46:1498-1508. [PubMed: 17705261] 
51. Dunn C, Brunetto M, Reynolds G, et al. Cytokines induced during chronic hepatitis B virus infection promote a pathway for NK cell-mediated liver damage. J Exp Med 2007;204:667-680. [PubMed: 17353365]

52. Malhi H, Barreyro FJ, Isomoto H, et al. Free fatty acids sensitise hepatocytes to TRAIL mediated cytotoxicity. Gut 2007;56:1124-1131. [PubMed: 17470478]

53. Czaja MJ. The future of GI and liver research: editorial perspectives. III. JNK/AP-1 regulation of hepatocyte death. Am J Physiol Gastrointest Liver Physiol 2003;284:G875-G879. [PubMed: 12736142]

54. Corazza N, Jakob S, Schaer C, et al. TRAIL receptor-mediated JNK activation and Bim phosphorylation critically regulate Fas-mediated liver damage and lethality. J Clin Invest 2006;116:2493-2499. [PubMed: 16955144]

55. Wang Y, Singh R, Lefkowitch JH, et al. Tumor necrosis factor-induced toxic liver injury results from JNK2-dependent activation of caspase-8 and the mitochondrial death pathway. J Biol Chem 2006;281:15258-15267. [PubMed: 16571730]

56. Chang L, Kamata H, Solinas G, et al. The E3 ubiquitin ligase itch couples JNK activation to TNFalphainduced cell death by inducing c-FLIP(L) turnover. Cell 2006;124:601-613. [PubMed: 16469705]

57. Schattenberg JM, Singh R, Wang Y, et al. JNK1 but not JNK2 promotes the development of steatohepatitis in mice. Hepatology 2006;43:163-172. [PubMed: 16374858]

58. Malhi H, Bronk SF, Werneburg NW, et al. Free fatty acids induce JNK-dependent hepatocyte lipoapoptosis. J Biol Chem 2006;281:12093-12101. [PubMed: 16505490]

59. Gunawan BK, Liu ZX, Han D, et al. c-Jun N-terminal kinase plays a major role in murine acetaminophen hepatotoxicity. Gastroenterology 2006;131:165-178. [PubMed: 16831600]

60. Szabo G, Mandrekar P, Dolganiuc A. Innate immune response and hepatic inflammation. Semin Liver Dis 2007;27:339-350. [PubMed: 17979071]

61. Chen Y, Wei H, Sun R, et al. Increased susceptibility to liver injury in hepatitis B virus transgenic mice involves NKG2D-ligand interaction and natural killer cells. Hepatology 2007;46:706-715. [PubMed: 17626270]

62. Henderson NC, Pollock KJ, Frew J, et al. Critical role of c-jun (NH2) terminal kinase in paracetamolinduced acute liver failure. Gut 2007;56:982-990. [PubMed: 17185352]

63. Liu ZX, Govindarajan S, Kaplowitz N. Innate immune system plays a critical role in determining the progression and severity of acetaminophen hepatotoxicity. Gastroenterology 2004;127:1760-1774. [PubMed: 15578514]

64. Tagami A, Ohnishi H, Hughes RD. Increased serum soluble Fas in patients with acute liver failure due to paracetamol overdose. Hepatogastroenterology 2003;50:742-745. [PubMed: 12828076]

65. Zhang H, Cook J, Nickel J, et al. Reduction of liver Fas expression by an antisense oligonucleotide protects mice from fulminant hepatitis. Nat Biotechnol 2000;18:862-867. [PubMed: 10932156]

66. Song E, Lee SK, Wang J, et al. RNA interference targeting Fas protects mice from fulminant hepatitis. Nat Med 2003;9:347-351. [PubMed: 12579197]

67. Miyoshi H, Rust C, Roberts PJ, et al. Hepatocyte apoptosis after bile duct ligation in the mouse involves Fas. Gastroenterology 1999;117:669-677. [PubMed: 10464144]

68. Faubion WA, Guicciardi ME, Miyoshi H, et al. Toxic bile salts induce rodent hepatocyte apoptosis via direct activation of Fas. J Clin Invest 1999;103:137-145. [PubMed: 9884343]

69. Sodeman T, Bronk SF, Roberts PJ, et al. Bile salts mediate hepatocyte apoptosis by increasing cell surface trafficking of Fas. Am J Physiol Gastrointest Liver Physiol 2000;278:G992-G999. [PubMed: 10859230]

70. Reinehr R, Becker S, Wettstein M, et al. Involvement of the Src family kinase yes in bile salt-induced apoptosis. Gastroenterology 2004;127:1540-1557. [PubMed: 15521021]

71. Higuchi H, Bronk SF, Takikawa Y, et al. The bile acid glycochenodeoxycholate induces trail-receptor 2/DR5 expression and apoptosis. J Biol Chem 2001;276:38610-38618. [PubMed: 11507096]

72. Higuchi H, Yoon JH, Grambihler A, et al. Bile acids stimulate cFLIP phosphorylation enhancing TRAIL-mediated apoptosis. J Biol Chem 2003;278:454-461. [PubMed: 12407100]

73. Higuchi H, Miyoshi H, Bronk SF, et al. Bid antisense attenuates bile acid-induced apoptosis and cholestatic liver injury. J Pharmacol Exp Ther 2001;299:866-873. [PubMed: 11714870] 
74. Canbay A, Higuchi H, Bronk SF, et al. Fas enhances fibrogenesis in the bile duct ligated mouse: a link between apoptosis and fibrosis. Gastroenterology 2002;123:1323-1330. [PubMed: 12360492]

75. Canbay A, Feldstein A, Baskin-Bey E, et al. The caspase inhibitor IDN-6556 attenuates hepatic injury and fibrosis in the bile duct ligated mouse. J Pharmacol Exp Ther 2004;308:1191-1196. [PubMed: 14617689]

76. Anan A, Baskin-Bey ES, Bronk SF, et al. Proteasome inhibition induces hepatic stellate cell apoptosis. Hepatology 2006;43:335-344. [PubMed: 16440346]

77. Bernstein H, Payne CM, Bernstein C, et al. Activation of the promoters of genes associated with DNA damage, oxidative stress, ER stress and protein malfolding by the bile salt, deoxycholate. Toxicol Lett 1999;108:37-46. [PubMed: 10472808]

78. Mencin A, Seki E, Osawa Y, et al. Alpha-1 antitrypsin Z protein (PiZ) increases hepatic fibrosis in a murine model of cholestasis. Hepatology 2007;46:1443-1452. [PubMed: 17668872]

79. Pianko S, Patella S, Ostapowicz G, et al. Fas-mediated hepatocyte apoptosis is increased by hepatitis $\mathrm{C}$ virus infection and alcohol consumption, and may be associated with hepatic fibrosis: mechanisms of liver cell injury in chronic hepatitis C virus infection. J Viral Hepat 2001;8:406-413. [PubMed: 11703571]

80. Hiramatsu N, Hayashi N, Katayama K, et al. Immunohistochemical detection of Fas antigen in liver tissue of patients with chronic hepatitis C. Hepatology 1994;19:1354-1359. [PubMed: 7514559]

81. Takaku S, Nakagawa Y, Shimizu M, et al. Induction of hepatic injury by hepatitis C virus-specific $\mathrm{CD} 8+$ murine cytotoxic T lymphocytes in transgenic mice expressing the viral structural genes. Biochem Biophys Res Commun 2003;301:330-337. [PubMed: 12565864]

82. Kronenberger B, Wagner M, Herrmann E, et al. Apoptotic cytokeratin 18 neoepitopes in serum of patients with chronic hepatitis C. J Viral Hepat 2005;12:307-314. [PubMed: 15850472]

83. Chou AH, Tsai HF, Wu YY, et al. Hepatitis C virus core protein modulates TRAIL-mediated apoptosis by enhancing Bid cleavage and activation of mitochondria apoptosis signaling pathway. $\mathrm{J}$ Immunol 2005;174:2160-2166. [PubMed: 15699147]

84. Zhu N, Ware CF, Lai MM. Hepatitis C virus core protein enhances FADD-mediated apoptosis and suppresses TRADD signaling of tumor necrosis factor receptor. Virology 2001;283:178-187. [PubMed: 11336543]

85. Ruggieri A, Harada T, Matsuura Y, et al. Sensitization to Fas-mediated apoptosis by hepatitis C virus core protein. Virology 1997;229:68-76. [PubMed: 9123879]

86. Prikhod'ko EA, Prikhod'ko GG, Siegel RM, et al. The NS3 protein of hepatitis C virus induces caspase-8-mediated apoptosis independent of its protease or helicase activities. Virology 2004;329:53-67. [PubMed: 15476874]

87. Iken K, Huang L, Bekele H, et al. Apoptosis of activated CD4+ and CD8+ T cells is enhanced by coculture with hepatocytes expressing hepatitis $\mathrm{C}$ virus (HCV) structural proteins through FasL induction. Virology 2006;346:363-372. [PubMed: 16336987]

88. Tsamandas AC, Thomopoulos K, Zolota V, et al. Potential role of bcl-2 and bax mRNA and protein expression in chronic hepatitis type B and C: a clinicopathologic study. Mod Pathol 2003;16:12731288. [PubMed: 14681329]

89. Liang X, Liu Y, Zhang Q, et al. Hepatitis B virus sensitizes hepatocytes to TRAIL-induced apoptosis through Bax. J Immunol 2007;178:503-510. [PubMed: 17182590]

90. Janssen HL, Higuchi H, Abdulkarim A, et al. Hepatitis B virus enhances tumor necrosis factor-related apoptosis-inducing ligand (TRAIL) cytotoxicity by increasing TRAIL-R1/death receptor 4 expression. J Hepatol 2003;39:414-420. [PubMed: 12927928]

91. Cahill A, Cunningham CC, Adachi M, et al. Effects of alcohol and oxidative stress on liver pathology: the role of the mitochondrion. Alcohol Clin Exp Res 2002;26:907-915. [PubMed: 12068261]

92. Lieber CS. The discovery of the microsomal ethanol oxidizing system and its physiologic and pathologic role. Drug Metab Rev 2004;36:511-529. [PubMed: 15554233]

93. Kurose I, Higuchi H, Miura S, et al. Oxidative stress-mediated apoptosis of hepatocytes exposed to acute ethanol intoxication. Hepatology 1997;25:368-378. [PubMed: 9021949]

94. Adachi M, Higuchi H, Miura S, et al. Bax interacts with the voltage-dependent anion channel and mediates ethanol-induced apoptosis in rat hepatocytes. Am J Physiol Gastrointest Liver Physiol 2004;287:G695-G705. [PubMed: 15044178] 
95. Enomoto N, Yamashina S, Kono H, et al. Development of a new, simple rat model of early alcoholinduced liver injury based on sensitization of Kupffer cells. Hepatology 1999;29:1680-1689. [PubMed: 10347108]

96. Yin M, Wheeler MD, Kono H, et al. Essential role of tumor necrosis factor alpha in alcohol-induced liver injury in mice. Gastroenterology 1999;117:942-952. [PubMed: 10500078]

97. Naveau S, Emilie D, Balian A, et al. Plasma levels of soluble tumor necrosis factor receptors p55 and p75 in patients with alcoholic liver disease of increasing severity. J Hepatol 1998;28:778-784. [PubMed: 9625312]

98. Spahr L, Giostra E, Frossard JL, et al. Soluble TNF-R1, but not tumor necrosis factor alpha, predicts the 3-month mortality in patients with alcoholic hepatitis. J Hepatol 2004;41:229-234. [PubMed: $15288471]$

99. Ji C, Deng Q, Kaplowitz N. Role of TNF-alpha in ethanol-induced hyperhomocysteinemia and murine alcoholic liver injury. Hepatology 2004;40:442-451. [PubMed: 15368449]

100. Ponnappa BC, Israel Y, Aini M, et al. Inhibition of tumor necrosis factor alpha secretion and prevention of liver injury in ethanolfed rats by antisense oligonucleotides. Biochem Pharmacol 2005;69:569-577. [PubMed: 15670576]

101. Menon KV, Stadheim L, Kamath PS, et al. A pilot study of the safety and tolerability of etanercept in patients with alcoholic hepatitis. Am J Gastroenterol 2004;99:255-260. [PubMed: 15046213]

102. Ma X, Svegliati-Baroni G, Poniachik J, et al. Collagen synthesis by liver stellate cells is released from its normal feedback regulation by acetaldehyde-induced modification of the carboxylterminal propeptide of procollagen. Alcohol Clin Exp Res 1997;21:1204-1211. [PubMed: 9347080]

103. Lluis JM, Colell A, Garcia-Ruiz C, et al. Acetaldehyde impairs mitochondrial glutathione transport in HepG2 cells through endoplasmic reticulum stress. Gastroenterology 2003;124:708-724. [PubMed: 12612910]

104. Ji C, Mehrian-Shai R, Chan C, et al. Role of CHOP in hepatic apoptosis in the murine model of intragastric ethanol feeding. Alcohol Clin Exp Res 2005;29:1496-1503. [PubMed: 16131858]

105. Nehra V, Angulo P, Buchman AL, et al. Nutritional and metabolic considerations in the etiology of nonalcoholic steatohepatitis. Dig Dis Sci 2001;46:2347-2352. [PubMed: 11713934]

106. Donnelly KL, Smith CI, Schwarzenberg SJ, et al. Sources of fatty acids stored in liver and secreted via lipoproteins in patients with nonalcoholic fatty liver disease. J Clin Invest 2005;115:1343-1351. [PubMed: 15864352]

107. Puri P, Baillie RA, Wiest MM, et al. A lipidomic analysis of nonalcoholic fatty liver disease. Hepatology 2007;46:1081-1090. [PubMed: 17654743]

108. Listenberger LL, Schaffer JE. Mechanisms of lipoapoptosis: implications for human heart disease. Trends Cardiovasc Med 2002;12:134-138. [PubMed: 12007739]

109. Barreyro FJ, Kobayashi S, Bronk SF, et al. Transcriptional regulation of Bim by FoxO3A mediates hepatocyte lipoapoptosis. J Biol Chem 2007;282:27141-27154. [PubMed: 17626006]

110. Karaskov E, Scott C, Zhang L, et al. Chronic palmitate but not oleate exposure induces endoplasmic reticulum stress, which may contribute to INS-1 pancreatic beta-cell apoptosis. Endocrinology 2006;147:3398-3407. [PubMed: 16601139]

111. Feldstein AE, Canbay A, Guicciardi ME, et al. Diet associated hepatic steatosis sensitizes to Fas mediated liver injury in mice. J Hepatol 2003;39:978-983. [PubMed: 14642615]

112. Canbay A, Taimr P, Torok N, et al. Apoptotic body engulfment by a human stellate cell line is profibrogenic. Lab Invest 2003;83:655-663. [PubMed: 12746475]

113. Iredale JP, Benyon RC, Pickering J, et al. Mechanisms of spontaneous resolution of rat liver fibrosis. Hepatic stellate cell apoptosis and reduced hepatic expression of metalloproteinase inhibitors. J Clin Invest 1998;102:538-549. [PubMed: 9691091]

114. Taimr P, Higuchi H, Kocova E, et al. Activated stellate cells express the TRAIL receptor-2/death receptor-5 and undergo TRAIL-mediated apoptosis. Hepatology 2003;37:87-95. [PubMed: 12500193]

115. Green DR, Kroemer G. Pharmacological manipulation of cell death: clinical applications in sight? J Clin Invest 2005;115:2610-2617. [PubMed: 16200193] 
116. Zhong Z, Theruvath TP, Currin RT, et al. NIM811, a mitochondrial permeability transition inhibitor, prevents mitochondrial depolarization in small-for-size rat liver grafts. Am J Transplant 2007;7:1103-1111. [PubMed: 17456198]

117. Pockros PJ, Schiff ER, Shiffman ML, et al. Oral IDN-6556, an antiapoptotic caspase inhibitor, may lower aminotransferase activity in patients with chronic hepatitis C. Hepatology 2007;46:324-329. [PubMed: 17654603]

118. Rodrigues CM, Fan G, Ma X, et al. A novel role for ursodeoxycholic acid in inhibiting apoptosis by modulating mitochondrial membrane perturbation. J Clin Invest 1998;101:2790-2799. [PubMed: 9637713]

119. Botla R, Spivey JR, Aguilar H, et al. Ursodeoxycholate (UDCA) inhibits the mitochondrial membrane permeability transition induced by glycochenodeoxycholate: a mechanism of UDCA cytoprotection. J Pharmacol Exp Ther 1995;272:930-938. [PubMed: 7853211]

\section{Acknowledgements}

Supported by National Institutes of Health grant DK 41876 and the Mayo Foundation. 


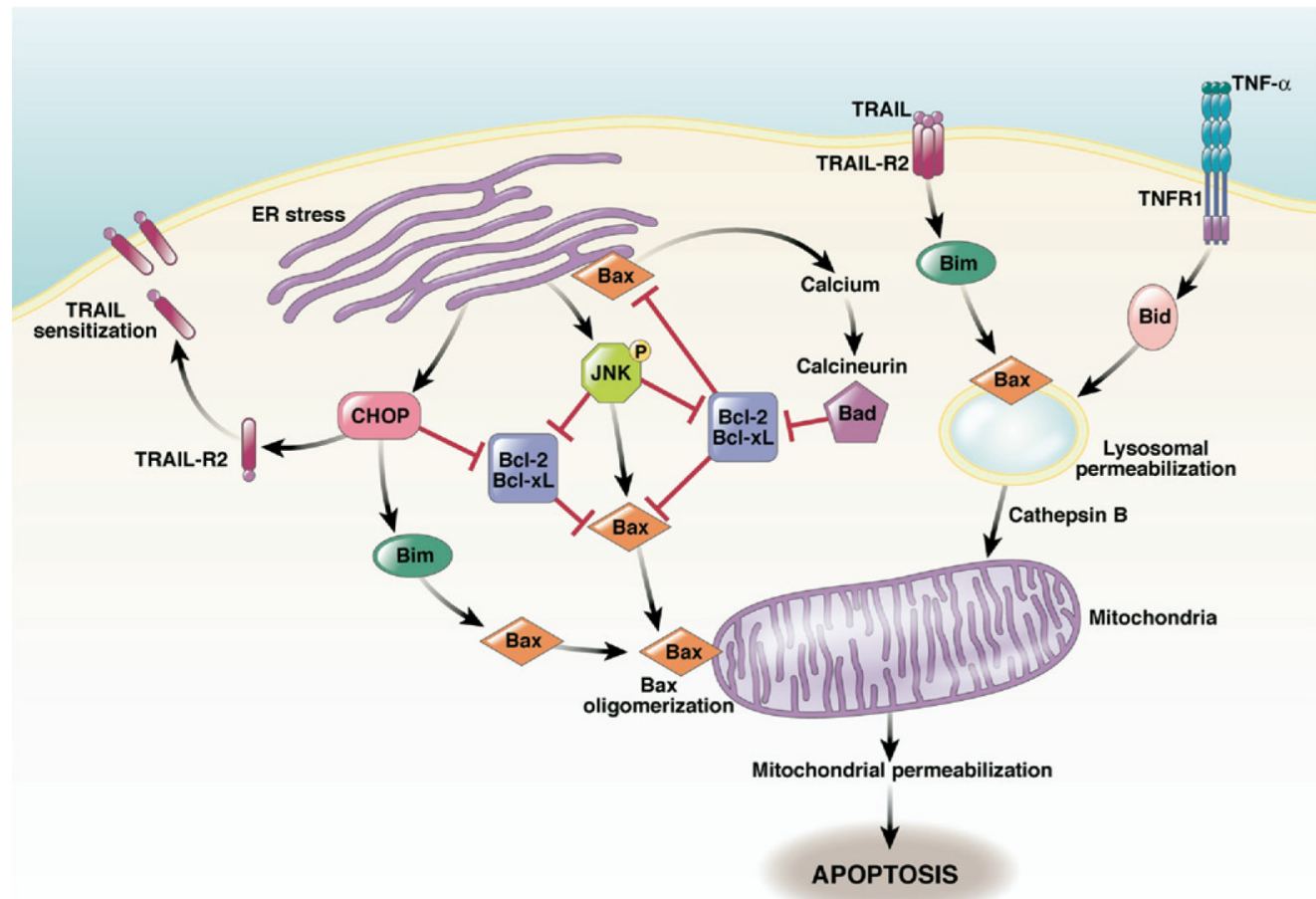

Figure 1.

Extrinsic and intrinsic pathways of hepatocyte apoptosis. The extrinsic pathway is activated by death receptors. Fas or TRAIL (depicted here) bind to their cognate receptors, leading to the formation of the death-inducing signaling complex (DISC), with caspase 8 activation, Bid cleavage, and subsequent mitochondrial permeabilization. Bim activation can also occur downstream of death receptor signaling, leading to Bax activation and mitochondrial permeabilization. The TNF- $\alpha$ signaling pathway also leads to Bid cleavage with lysosomal permeabilization, leading to release of lysosomal contents and mitochondrial permeabilization. The intrinsic pathway of cell death can be initiated by myriad intracellular stressors that can activate the ER stress pathway, lysosomal permeabilization, or JNK activation. These cascades lead to inhibition of the antiapoptotic proteins (Bcl-xL, Bcl-2) and activation of the proapoptotic proteins (Bax, Bim, Bad, Bid). Mitochondrial permeabilization occurs eventually and is required for hepatocyte apoptosis. 


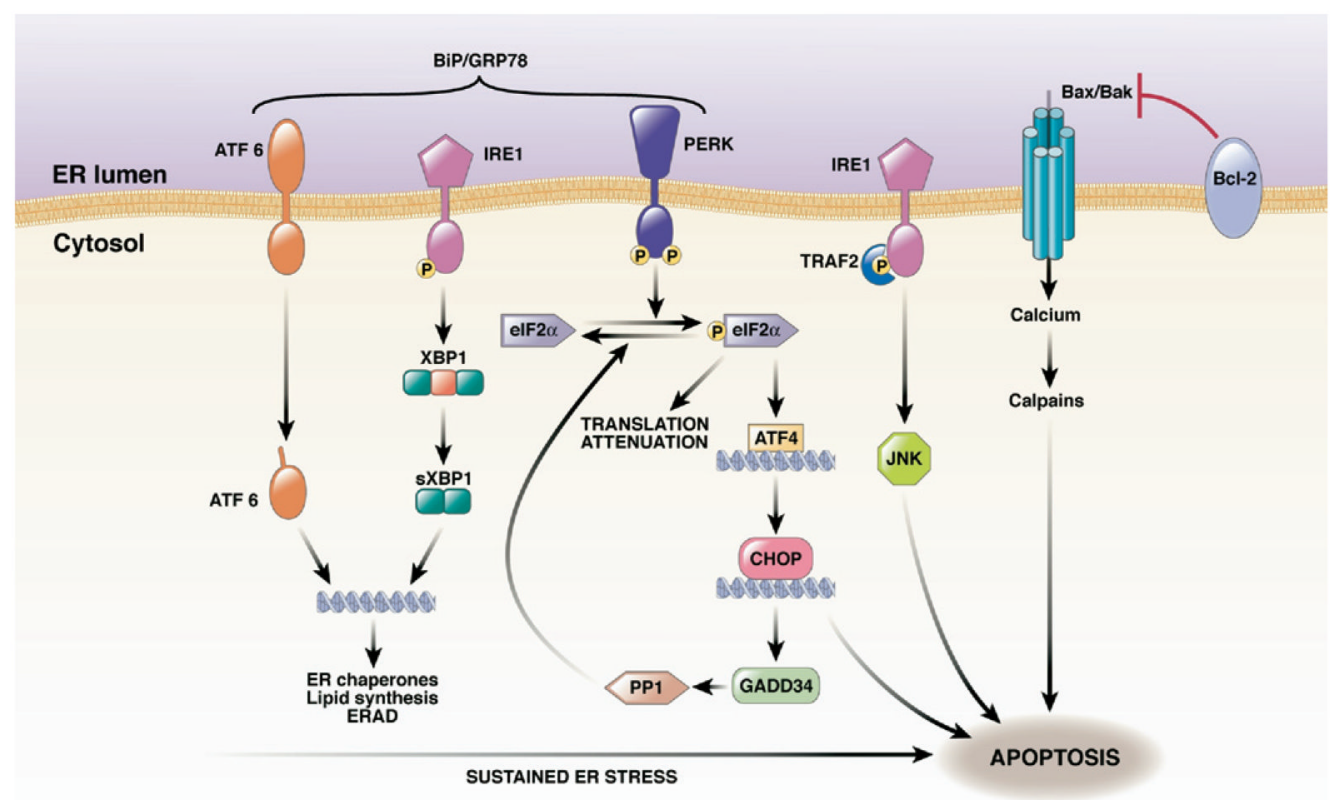

Figure 2.

The ER stress pathway. The ER membrane contains 3 stress transducers: IRE1, ATF6, and PERK. Their activation is controlled by the ER molecular chaperone immunoglobulin-binding protein of B cells (BiP/GRP78). Release from BiP binding activates the ER stress transducers. IRE1 contains a cytoplasmic kinase domain and an endoribonuclease domain. The latter cleaves XBP1 to spliced XBP1 (sXBP1), leading to transcriptional activation of adaptive molecules to overcome ER stress, such as ER chaperones, lipid synthesis, and increasing ERassociated degradation (ERAD). PERK activation leads to phosphorylation of eukaryotic translation initiation factor $2 \alpha$, leading to global translation attenuation. ATF6 also transcriptionally activates UPR target genes. These processes collectively function to overcome and correct ER stress. In the face of sustained ER stress, apoptotic machinery becomes activated. PERK leads to selective translation of ATF4, transcription of CHOP, and activation of the apoptotic machinery. CHOP can affect Bim levels and death receptor 5 levels. IRE1 can also activate JNK. Active Bax/Bak can permeabilize the ER membrane, leading to calcium release, activation of calpains, and apoptosis. Growth arrest and DNA damage protein 34 (GADD34) associates with protein phosphatase 1 (PP1), leading to dephosphorylation of eukaryotic translation initiation factor $2 \alpha$ and attenuation of the UPR. 


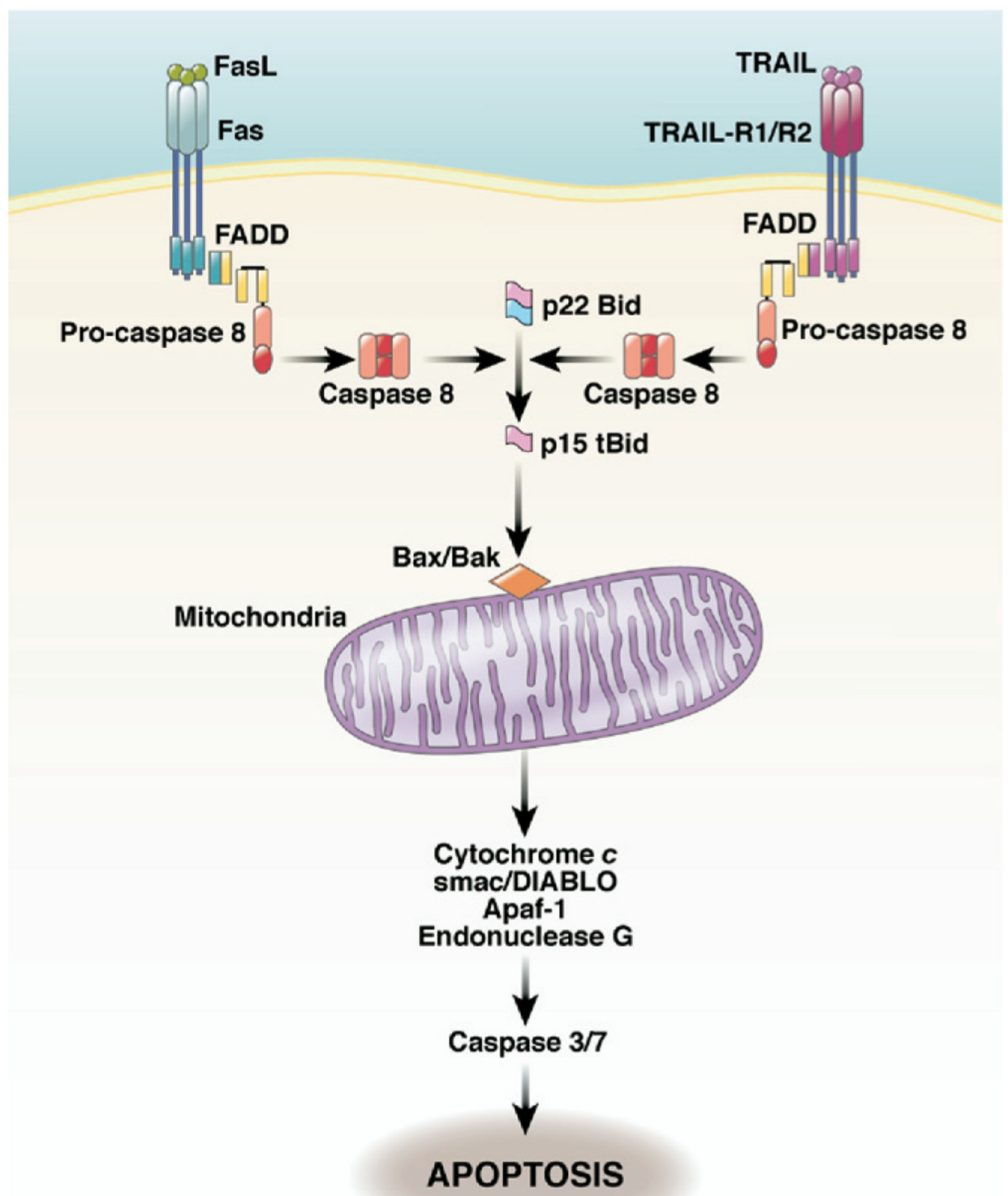

Figure 3.

Fas and TRAIL receptor signaling. Fas and TRAIL receptors activate conserved signaling pathways on receptor ligand interactions. FADD binds to the intracellular death domain (DD) containing trimerized receptor. FADD also contains a death effector domain (DED) that leads to activation of caspase 8 by cleavage and homodimerization of procaspase 8 . Caspase 8 leads to cleavage of Bid to $\mathrm{tBid}$ and downstream mitochondrial permeabilization. Mitochondrial contents, including cytochrome $c$, SMAC/DIABLO, APAF-1, and endonuclease G, are released, leading to the activation of caspase 3/7. Caspase 3/7 leads to cleavage of cellular proteins and the characteristic apoptotic morphology. 


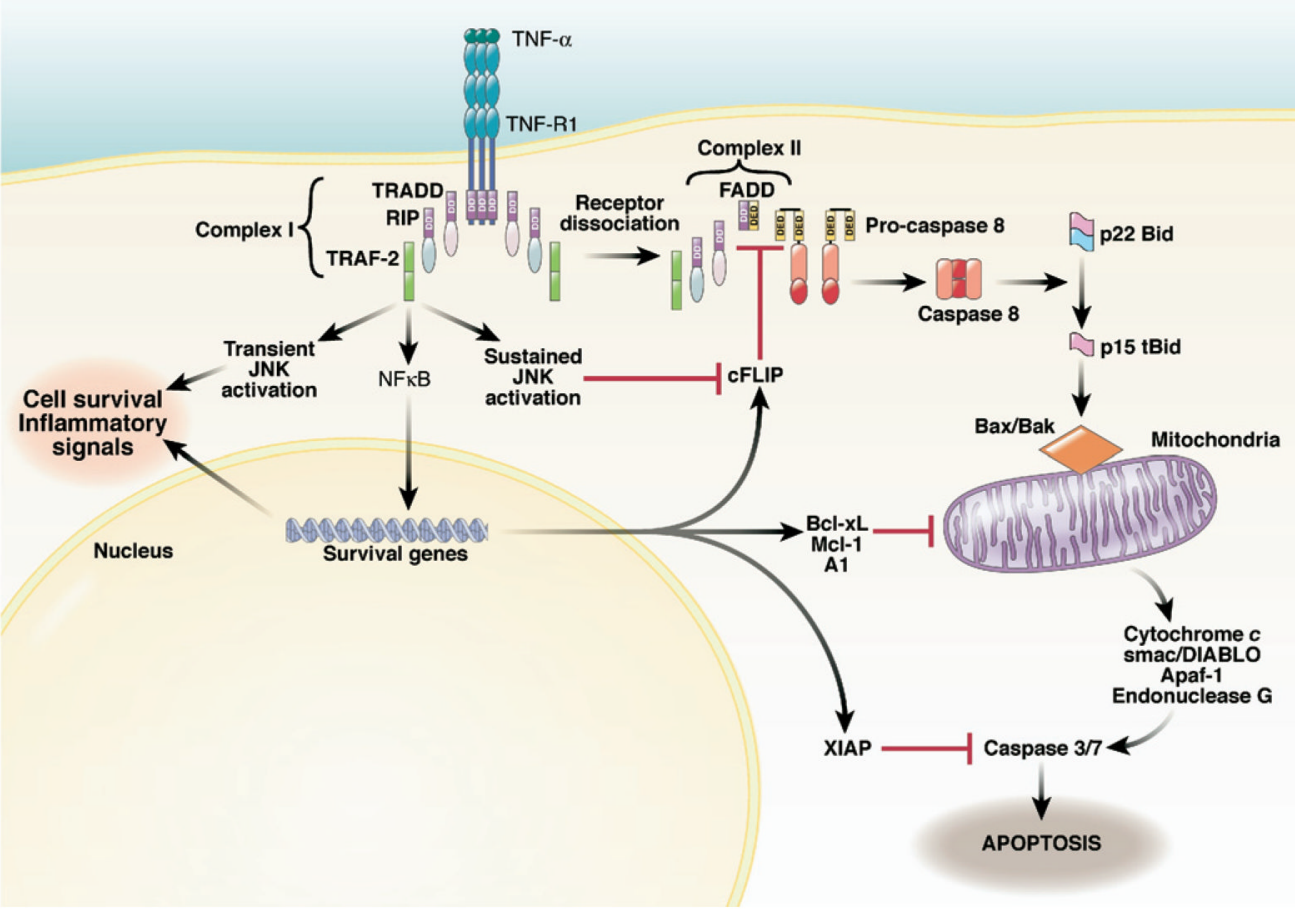

Figure 4.

TNF- $\alpha$ signaling. TNF- $\alpha$ binds to the extracellular domain of its cognate receptor, TNFR1. The intracellular portion of TNFR1 contains a death domain (DD). This interacts with the DD of TNFR1-associated death domain protein (TRADD) and recruits receptor interacting protein also via its DD, and TNF receptor-associated factor (TRAF2) via its kinase domain or an intermediate domain. This signal transduction complex is referred to as complex 1 . Nuclear factor $\kappa \mathrm{B}(\mathrm{NF}-\kappa \mathrm{B})$ activation and transient JNK activation occur downstream of complex 1. Active NF- $\kappa \mathrm{B}$ translocates to the nucleus, leading to the transcription of antiapoptotic genes. Among its known target genes are cellular FLICE-like inhibitory protein (cFLIP), Bcl-xL, Mcl-1, A1, and XIAP, which regulate apoptosis at multiple levels. The early and transient activation of JNK also promotes survival. Sustained JNK activation requires receptor interacting protein; although the exact pathways are not fully known, oxidative stress is recognized as one mediator of sustained JNK activation. TRADD, receptor interacting protein, and TRAF2 then undergo receptor dissociation, recruit FADD via its DD. FADD also contains a death effector domain (DED) that leads to activation of caspase 8, cleavage of Bid to tBid, and downstream mitochondrial permeabilization. 




Figure 5.

The central role of hepatocyte apoptosis in liver injury. Vulnerable hepatocytes undergo apoptosis when stressed. Apoptosis can be initiated via Kupffer cell release of TNF- $\alpha$, leading to activation of JNK. Activated NK and NK T cells release Fas or TRAIL, and interferon gamma, which up-regulates Fas or TRAIL release, leading to death receptor-mediated hepatocyte apoptosis. Hepatocyte apoptosis can also occur via activation of the intrinsic pathway (not shown here). Apoptotic hepatocytes are engulfed Kupffer cells, leading in turn to their activation. Activated Kupffer cells secrete TNF- $\alpha$, interleukins, and interferon to promote the inflammatory response. They also secrete transforming growth factor $\beta$, leading to activation of stellate cells. Stellate cells can also be directly activated by apoptotic bodies. Activated stellate cells secrete collagen type I, leading to liver fibrosis. Attenuation of hepatocyte apoptosis, or forced apoptosis of activated stellate cells, such as with proteasomal inhibitors or TRAIL, can lead to resolution of fibrosis. 
Table 1

The Bcl-2 Family Proteins

\begin{tabular}{llc}
\hline & \multicolumn{2}{c}{ Bcl-2 Family Proteins } \\
\hline & & Proapoptotic \\
\cline { 2 - 3 } Antiapoptotic & BH3 only & Multidomain \\
\hline Bcl-xL & Bid & Bax \\
Mcl-1 & Bim & Bak \\
Bcl-w & Puma & Bok \\
Bcl-2 & Noxa & Bcl- $\mathrm{x}_{\mathrm{s}}$ \\
A1 & Bad & \\
Boo & Bik & \\
& Bmf & \\
\hline
\end{tabular}

